Editorial

\title{
Biomedical Applications of Polylactide (PLA) and Its Copolymers
}

\author{
Gaetano Giammona * and Emanuela Fabiola Craparo * \\ Laboratory of Biocompatible Polymers, Department of "Scienze e Tecnologie Biologiche, Chimiche e \\ Farmaceutiche" (STEBICEF), University of Palermo, Via Archirafi, 3290123 Palermo, Italy \\ * Correspondence: gaetano.giammona@unipa.it (G.G.); emanuela.craparo@unipa.it (E.F.C.)
}

Received: 19 April 2018; Accepted: 21 April 2018; Published: 23 April 2018

Currently, the interest of the scientific community towards Polylactide (PLA), blended and/or functionalized with other biopolymers, is rapidly increasing due to its great potential as starting material for biomedical applications. This favorable approval arises from its excellent properties, such as biocompatibility, biodegradability, and tunable mechanical and physicochemical properties, as well as the chemical susceptibility that allows to obtain novel polymeric materials. Moreover, PLA and its copolymers can be appropriately processed and engineered to allow a desired biomedical application.

In this special issue, current experimental research focused on several applications of PLA-based materials, such as the production of drug delivery systems, applicable in controlled and/or targeted drug release, and in the fabrication of bioresorbable scaffolds for tissue engineering in regenerative medicine, is reported.

In their study, $\mathrm{Li}$ et al. reported the therapeutic potential of an antimicrobial peptide, KKVVFWVKFK-CONH 2 (KSL-W), when it is loaded into poly (lactic-co-glycolic) acid (PLGA)/chitosan (CS) composite microspheres as an effective drug delivery system in the treatment of oral infectious diseases such as periodontitis, and also within bone graft substitutes for alveolar bone augmentation, for long-acting bacterial resistance [1].

Craparo et al. reported a study on a PLA-based nanoparticulate carrier margination in relation to $\mathrm{RBC}$ concentration (hematocrit) and pressure drop by using a microfluidic system mimicking the hydrodynamic conditions of human microcirculation in vitro [2], highlighting the importance of taking into account RBC-drug carrier interactions and physiological conditions in microcirculation when planning a drug delivery strategy based on systemically administered carriers.

Oledzka et al. designed and proposed a new multifunctional composite based on PLA as a promising bone substitute material for patients with bone tumors or bone metastasis [3]. The material was successfully synthesized starting from hydroxyapatite porous granules doped with selenite ions and bisphosphonate-conjugated biodegradable branched copolymers, obtained by the ring-opening polymerization (ROP) reaction between a hyperbranched bis-MPA polyester-16-hydroxyl initiator, $\mathrm{Sn}(\mathrm{Oct})_{2}$, in the presence of L,L-lactide (LLA) and $\varepsilon$-caprolactone (CL).

Most recent advances in tissue engineering in the fields of oral surgery and dentistry have aimed to restore hard and soft tissues. Ceccarelli et al. described the realization and the characterization of two different inorganic scaffolds based on PLGA acid alone or in combination with hydroxyapatite (PLGA/HA-Alos), both in vitro and in vivo, demonstrating that the osteoconductivity of PLGA/HA-Alos and the efficacy of scaffolds in promoting bone-healing in the sinus lift were increased [4]. Krucińska demonstrated the biological properties of low-toxicity PLGA and PLGA/synthetic poly([r,s]-3-hydroxybutyrate) (PHB) fibrous nanocomposite implants for osseous tissue regeneration, by reporting in detail the evaluation of potential biotoxicity and bioactivity $[5,6]$.

Starting from PLGA copolymer, the development of a novel coating solution for surgical sutures, containing the antibacterial substance totarol in combination with PLGA, was described by Reimbold 
et al. [7]. In particular, it was found that non-absorbable monofilament and multifilament sutures coated with different amounts and ratios of totarol and PLGA were able to inhibit the growth of Staphylococcus aureus showing a great potential to reduce the risk of Surgical site infections (SSIs) and post-operative biofilm-formation on suture material, without adverse effects on tissue.

Moreover, PLA also possesses unique properties to be used for the realization of intelligent fabric and/or packaging films releasing particles. Walczac et al. have explored the characteristics of a nonwoven fabric based on the poly(lactide-co-glycolide-co-trimethylene carbonate) copolymer (PLLAGLTMC), with thermally induced shape memory and a transition temperature around human body temperature, by thermo-mechanical, morphological, and shape memory analyses [8]. In their paper, $\mathrm{Li}$ et al., have reported the development of an antimicrobial packaging film from PLA blends incorporating titanium dioxide $\left(\mathrm{TiO}_{2}\right)$ and silver nanoparticles (nano-Ag) by using a solvent volatilization method, which showed favorable properties compared to pure PLA films [9].

\section{References}

1. Li, Y.; Na, R.; Wang, X.; Liu, H.; Zhao, L.; Sun, X.; Ma, G.; Cui, F. Fabrication of Antimicrobial Peptide-Loaded PLGA/Chitosan Composite Microspheres for Long-Acting Bacterial Resistance. Molecules 2017, 22, 1637. [CrossRef] [PubMed]

2. Craparo, E.; D'Apolito, R.; Giammona, G.; Cavallaro, G.; Tomaiuolo, G. Margination of Fluorescent Polylactic Acid-Polyaspartamide based Nanoparticles in Microcapillaries In Vitro: the Effect of Hematocrit and Pressure. Molecules 2017, 22, 1845. [CrossRef] [PubMed]

3. Oledzka, E.; Pachowska, D.; Orłowska, K.; Kolmas, J.; Drobniewska, A.; Figat, R.; Sobczak, M. Pamidronate-Conjugated Biodegradable Branched Copolyester Carriers: Synthesis and Characterization. Molecules 2017, 22, 1063. [CrossRef] [PubMed]

4. Ceccarelli, G.; Presta, R.; Lupi, S.; Giarratana, N.; Bloise, N.; Benedetti, L.; Cusella De Angelis, M.; Rodriguez y Baena, R. Evaluation of Poly(Lactic-co-glycolic) Acid Alone or in Combination with Hydroxyapatite on Human-Periosteal Cells Bone Differentiation and in Sinus Lift Treatment. Molecules 2017, 22, 2109. [CrossRef] [PubMed]

5. Krucińska, I.; Żywicka, B.; Komisarczyk, A.; Szymonowicz, M.; Kowalska, S.; Zaczyńska, E.; Struszczyk, M.; Czarny, A.; Jadczyk, P.; Umińska-Wasiluk, B.; et al. Biological Properties of Low-Toxicity PLGA and PLGA/PHB Fibrous Nanocomposite Implants for Osseous Tissue Regeneration. Part I: Evaluation of Potential Biotoxicity. Molecules 2017, 22, 2092. [CrossRef] [PubMed]

6. Żywicka, B.; Krucińska, I.; Garcarek, J.; Szymonowicz, M.; Komisarczyk, A.; Rybak, Z. Biological Properties of Low-Toxic PLGA and PLGA/PHB Fibrous Nanocomposite Scaffolds for Osseous Tissue Regeneration. Evaluation of Potential Bioactivity. Molecules 2017, 22, 1852. [CrossRef] [PubMed]

7. Reinbold, J.; Uhde, A.; Müller, I.; Weindl, T.; Geis-Gerstorfer, J.; Schlensak, C.; Wendel, H.; Krajewski, S. Preventing Surgical Site Infections Using a Natural, Biodegradable, Antibacterial Coating on Surgical Sutures. Molecules 2017, 22, 1570. [CrossRef] [PubMed]

8. Walczak, J.; Chrzanowski, M.; Krucińska, I. Research on a Nonwoven Fabric Made from Multi-Block Biodegradable Copolymer Based on L-Lactide, Glycolide, and Trimethylene Carbonate with Shape Memory. Molecules 2017, 22, 1325. [CrossRef] [PubMed]

9. Li, W.; Zhang, C.; Chi, H.; Li, L.; Lan, T.; Han, P.; Chen, H.; Qin, Y. Development of Antimicrobial Packaging Film Made from Poly(Lactic Acid) Incorporating Titanium Dioxide and Silver Nanoparticles. Molecules 2017, 22, 1170. [CrossRef] [PubMed]

(C) 2018 by the authors. Licensee MDPI, Basel, Switzerland. This article is an open access article distributed under the terms and conditions of the Creative Commons Attribution (CC BY) license (http://creativecommons.org/licenses/by/4.0/). 